\title{
Resignação como efeito trágico: a teoria schopenhaueriana da tragédia
}

\author{
Resignation as tragic effect: Schopenhauer's theory of tragedy
}

\section{José Fernandes Weber}

Professor do Programa de Pós-Graduação em Filosofia da Universidade Estadual de Londrina

E-mail:jweber@uel.br

Resumo: A fim de aclarar a conjunção entre o trágico e a resignação, em primeiro lugar será apresentado o significado da resignação como consequência do trágico a partir da comparação com o sublime dinâmico. Posteriormente será explorada brevemente a contraposição entre a tragédia antiga e moderna, momento em que também será considerada a acusação de Nietzsche segundo a qual Schopenhauer não teria percebido a dimensão afirmativa da tragédia grega.

Palavras-chave: Schopenhauer; Resignação; Tragédia; Sublime.

\begin{abstract}
To make clear the conjunction between tragic and resignation, at first will be presented the signification of resignation as a consequence of the tragic from the comparison with dynamic sublime. Before then will be explored the contraposition between antike and modern tragedy, when also will be considered Nietzsche's accusation according to wich Schopenhauer would not have perceived the affirmative dimension of Greek tragedy.
\end{abstract}

Keywords: Schopenhauer; Resignation; Tragedy; Sublime. 
CORO: O não ser nato / Vence todo argumento. Mas, / advindo à luz, / o rápido retroceder / ao ponto de origem / é o bem de segunda magnitude. / Quando a neofase passa e a vanidade / da irreflexão, / qual golpe pluridor se exclui, / qual pesar não se inclui? / Revolta, inveja, discordância, guerras, / mortes. E o lote conclusivo: / impotente, intratável, execrável, / a desprezível senescência, / vazia-de-amigos, / onde / sem faltar nenhum / males / germinam / males. (1225-1238) ${ }^{1}$

$\mathrm{N}$

uma passagem bastante conhecida de $O$ nascimento da tragédia, em que há uma referência implícita ao ensinamento contido nesta passagem da tragédia Édipo em Colono, pode-se ler: "O melhor de tudo é para ti inteiramente inatingível: não ter nascido, não ser, nada ser. Depois disso, porém, o melhor é logo morrer"2 ${ }^{2}$ É o que, ao juízo de Nietzsche, ensinaria a sabedoria popular grega, expressa na figura de Sileno, mas não a sabedoria trágica, que diria: "A pior coisa de todas é para eles morrer logo; a segunda pior é simplesmente morrer um dia"3.

No Fausto, caracterizado por Goethe como uma tragédia ${ }^{4}$, após o lamento a respeito da falta de fundamento dos esforços humanos e do sem sentido da vida 5 , do sentido recobrado e do movimento vital engendrado por meio do pacto demoníaco ${ }^{6}$, Fausto jaz. Frente a ele, Mefistófeles - "o Gênio que sempre nega!"7, cujas obras criam ilusão, meramente ilusão, e que restituem ao processo uma espécie de síntese invertida, oca, pois das teses e antíteses da vida, "nada" se conclui, ou melhor, conclui-se "nada" - sentencia:

MEFISTÓFELES: Passou! Palavra estúpida! / Passou por quê? Tolice! / Passou, nada integral, insípida mesmice! / De que serve a perpétua obra criada, / Se logo algo a arremessa para o Nada? / Pronto, passou! Onde há nisso um sentido? / Ora! É tal qual nunca houvesse existido, / E como se existisse, embora, ronda em giro. / Pudera! 0 Vácuo-Eterno àquilo então prefiro ${ }^{8}$.

${ }^{1}$ SÓFOCLES. Édipo em Colono, p. 95-96.

${ }^{2}$ NIETZSCHE, F.W. O nascimento da tragédia ou helenismo e pessimismo, p. 36.

${ }^{3}$ Idem, p. 37.

${ }^{4}$ Atesta-o não apenas o tratamento, mas o próprio subtítulo da obra, precisamente: uma tragédia!

${ }^{5}$ GOETHE, J.W. Fausto, uma tragédia - parte I, p 63-69.

${ }^{6}$ Idem, pp. 169-179.

${ }^{7}$ GOETHE, J.W. Idem, p. 139.

${ }^{8}$ GOETHE, J.W. Fausto, uma tragédia - Tomo II, p. 987.

Resignação como efeito trágico: a teoria schopenhaueriana da tragédia 
Nestas passagens, respectivamente de Édipo em Colono e de Fausto, Sófocles e Goethe expressam, de um modo condensado e dificilmente superável, o drama que o espetáculo trágico encena: quanto valerá isso que é destinado a perecer, que não pode não perecer, cujo modo próprio de ser se configura sob o signo da aniquilação? Este drama não é outro que o próprio drama da individuação, do vira-ser, do tornar-se um e, por fim, do desaparecer.

Um tratamento técnico da tragédia, cujo modelo exemplar é a Poética de Aristóteles, preocupado com a elucidação da criação poética, mais precisamente, com a determinação dos "[...] elementos da arte trágica” (SZONDI, 2004, p. 23), convertido em ensinamento douto pelos comentadores, chegando a se constituir em um conjunto prescritivo de técnicas para a criação de um espetáculo trágico, da arte poética ${ }^{9}$, não poderia jamais chegar a considerar a pergunta filosófica sobre o sentido do trágico. Daí Peter Szondi, na introdução do seu livro Ensaio sobre o trágico, afirmar: "Desde Aristóteles há uma poética da tragédia; apenas desde Schelling, uma filosofia do trágico"10. A diferença entre ambas se assemelha a dois indivíduos que, apanhados por uma tempestade em alto mar, põem-se a considerar, o primeiro, os componentes químicos da água, o outro, a fatalidade e a morte iminente.

Dentre as mais eminentes "filosofias do trágico" do início do século XIX, a de Schopenhauer ocupa uma posição bastante peculiar, pois não concebe o trágico como evento de conciliação ou reconciliação, razão pela qual pode ser chamada de uma filosofia do trágico da não-conciliação. Diferentemente de Schelling11, para o qual o trágico revelaria um telos que evidenciaria a afirmação da liberdade (transcendental) à custa do declínio do herói (empírico) e, posteriormente, a beleza como unificação do real e do ideal; de Hölderlin, em que o trágico expressa o conflito entre arte e natureza, cujo resultado efetivaria a unificação entre ambas; de Hegel, para quem a tragicidade e a dialética coincidem, pois o processo trágico é a dialética da eticidade, expressando a síntese de seus elementos contraditórios; por fim, diferentemente do jovem Nietzsche, de acordo com o qual a tragédia grega, o trágico, expressava a reconciliação do homem com a natureza; para Schopenhauer

\footnotetext{
9 Trata-se dos exageros do formalismo do classicismo francês que concebia a submissão às regras aristotélicas como um canon sagrado para a criação poética. Shakespeare, insubmisso, era chamado de "Bárbaro do Norte".

10 SZONDI, P. Ensaio sobre o trágico, p. 23.

${ }^{11}$ A respeito desta caracterização, ver: SZONDI, P. Ensaio sobre o trágico, pp.29-58.
} 
“[...] a verdadeira tendência da tragédia [...] permanece sendo a exigência do desvio da Vontade de vida"12.

Caso se pretenda objetar a validade de interpretar a filosofia do trágico de Schopenhauer a partir da ideia de não conciliação, pois o mesmo Schopenhauer destaca na tragédia a tendência à "[...] elevação por sobre todos os fins e bens da vida, o desvio desta e dos seus atrativos e a indicação aí presente para um outro tipo de existência"13, bastaria dizer que tal elevação não opera uma conciliação ou uma síntese, funcionando, antes, no seu nível mais baixo, como uma suspensão, no seu nível mais intenso, como um apagamento, uma aniquilação, visto pretender justamente um desvio da Vontade de vida e dos seus atrativos. Contudo, a aniquilação do mundo, a negação da vontade não será alcançada plenamente, duradouramente, via contemplação estética, pois esta possibilita apenas um desprendimento provisório da vontade ${ }^{14}$. Além do que, esse "outro tipo de existência", é completamente inconcebível por nós. Tal deslocamento, Schopenhauer chama-o de elevação, constitui a tendência peculiar a todo o trágico, a partir do qual brota o "[...] conhecimento de que o mundo, a vida não pode proporcionar-nos prazer verdadeiro algum, portanto, nosso apego a ela não vale a pena: nisto consiste o espírito trágico: ele conduz por consequência à resignação"15.

A esse respeito, cabe a introdução de uma importante distinção. No parágrafo 51 do Tomo I, depois de apresentar a caracterização da tragédia como o "ápice da arte poética", como a "suprema realização poética", e de definir seu objetivo como sendo "[...] a exposição do lado terrível da vida, a saber, o inominado sofrimento, a miséria humana, o triunfo da maldade, o império cínico do acaso, a queda inevitável do justo e do inocente", e mostrar que o conhecimento haurido na tragédia “[...] purifica e enobrece o indivíduo pelo sofrimento", ou seja, o fenômeno não mais ilude, Schopenhauer conclui:

\footnotetext{
12 SCHOPENHAUER, A. MVR II, § 37, p. 522.

13 Idem.

14 Quando trata do gênio e da especificidade da sua atividade, a contemplação, Schopenhauer sugere que ele "[...] só é capaz de uma apreensão objetiva e profunda do mundo exterior quando desprendeu-se, ao menos provisoriamente, dessa sua raiz" (SCHOPENHAUER, A. MVR II, § 31, p. 456).

15 SCHOPENHAUER, A. MVR II, § 37, p. 520.

Resignação como efeito trágico: a teoria schopenhaueriana da tragédia
} 
Com isso, os até então poderosos motivos perdem o seu poder e, em vez deles, o conhecimento perfeito da essência do mundo, atuando como quietivo da vontade, produz resignação, a renúncia, não apenas da vida, mas de toda a Vontade de vida mesma ${ }^{16}$.

Se é comum ao Tomo I e aos Suplementos conceber o "efeito trágico" como resignação, parece haver nessa passagem a identificação entre resignação e renúncia da Vontade. Nos Suplementos, resignação permanece ligada a um campo semântico mais restrito, não menos significativo, porém, não chegando a ser pensada como renúncia no sentido amplo e radical do termo. A que se deve tal diferença?

Se a exigência que o trágico impõe é o desvio da vontade vida, isso não quer dizer, contudo, que tal exigência seja realizada integralmente na contemplação estética. Conduzir à resignação não quer dizer, já por si só, que a negação perdure. Ou, para ser mais preciso: se no plano da intensidade é possível sustentar que a contemplação efetiva a negação da Vontade, o que não poderia ser negado tendo em vista o que o próprio Schopenhauer afirma, contudo, no plano da duração, o seu alcance é limitado, pois ela não é duradoura.

O estado de contemplação estética faz desparecer felicidade e infelicidade. Tornamo-nos, não indivíduo, mas puro sujeito do conhecimento, livrando-nos do serviço da Vontade. Libertamo-nos do querer. Este estado, Schopenhaur chama-o de "[...] bem-aventurança do intuir destituído de vontade"17. Portanto, há negação da Vontade na contemplação estética. Mas, pergunta-se o filósofo:

[...] quem tem a força para nele se manter por longo tempo? Assim que surge novamente na consciência uma relação com a vontade, com a nossa pessoa, precisamente dos objetos intuídos puramente, o encanto chega ao fim. Recaímos no conhecimento regido pelo principio de razão. Não mais conhecemos a Ideia, mas a coisa isolada, elo de uma cadeia à qual nós mesmos pertencemos. De novo estamos abandonados às nossas penúrias ${ }^{18}$.

Por essa razão, parece ser importante levar em consideração a distinção acima proposta entre a intensidade e a duração na discussão sobre a negação da Vontade. Da mesma maneira, seria preciso atentar para o sentido da utilização do

\footnotetext{
${ }^{16}$ SCHOPENHAUER, A. MVR I, § 51, p. 333.

${ }^{17}$ SCHOPENHUAER, A. MVR I, § 38, p. 269.

18 Ibidem.
} 
termo resignação. Assim, sou da opinião de que a mudança de tônica a respeito do efeito da tragédia, do Tomo I de $O$ Mundo para os Suplementos, resulta da compreensão de que a resignação é o primeiro momento da teoria da negação da Vontade, um momento de "reconhecimento" sobre o sentido do sofrimento, para usar a expressão cunhada por Aristóteles para definir o processo pelo qual passa o herói trágico quando se dá conta do que está a acontecer há muito, e que somente agora ele percebe, "reconhece”. Como afirma Aristóteles: “[...] a modificação que faz passar da ignorância ao conhecimento"19. Igualmente importante é destacar que tal reconhecimento não dá acesso apenas a um conhecimento sobre o sentido individual da ação do herói, e sim, sobre a totalidade: o humano e o divino, ou seja, o cosmos. $\mathrm{Na}$ acepção schopenhaueriana, sobre a totalidade do mundo. A resignação é, portanto, o primeiro momento, provisório, para aquilo que a ascese efetivará, duradouramente. 0 que se apreende instantaneamente via contemplação estética, adquire-se gradativamente, mas também intensivamente e duradouramente mediante a ascese.

A fim de aclarar a conjunção entre o trágico e a resignação, opto, em primeiro lugar, por aclarar o significado da resignação como consequência do trágico a partir da comparação com o sublime dinâmico, para posteriormente explorar brevemente a contraposição entre a tragédia antiga e moderna, momento em que também será considerada a acusação de Nietzsche segundo a qual Schopenhauer não teria percebido a dimensão afirmativa da tragédia grega.

\section{I - Trágico, sublime dinâmico, resignação}

No capítulo 37 dos Suplementos, em dois momentos, Schopenhauer sugere uma conexão profunda entre o trágico e o sublime. Diz ele, na primeira ocasião: "Nosso prazer na TRAGÉDIA não pertence ao sentimento do belo, mas ao do sublime; sim, é o grau mais elevado desse sentimento" 20 . Na segunda, arremata: “(...) o efeito da tragédia é análogo àquele do sublime dinâmico"21.

Se nosso prazer na tragédia não pertence ao sentimento do belo, mas ao do sublime, a primeira exigência consiste em mostrar o modo como Schopenhauer

${ }^{19}$ ARISTÓTELES, Poética, p. 105.

${ }^{20}$ SCHOPENHAUER, A. MVR II, § 37, p. 519.

${ }^{21}$ Idem, p. 520.

Resignação como efeito trágico: a teoria schopenhaueriana da tragédia 
concebe o sublime. Na sua acepção mais elementar, contudo com alguns deslocamentos importantes apresentados logo adiante, Schopenhauer retoma a compreensão kantiana do sublime. No parágrafo 28 da Crítica da Faculdade do juízo, intitulado Da natureza como um poder, Kant apresenta aquela que é provavelmente a mais marcante e influente definição do sublime já dada. Diz ele:

Rochedos audazes sobressaindo-se por assim dizer ameaçadores, nuvens carregadas acumulando-se no céu, avançando com relâmpagos e estampidos, vulcões em sua interia força destruidora, furacões com a devastação deixada para trás, o ilimitado oceano revolto, uma alta queda d'água de um rio poderoso etc. tornam a nossa capacidade de resistência de uma pequenez insignificante em comparação com o seu poder. Mas o seu espetáculo só se torna mais atraente quanto mais terrível ele é, contanto que, somente, nos encontremos em segurança; e de bom grado denominamos estes objetos sublimes, porque eles elevam a fortaleza da alma acima dos eu nível médio e permitem descobrir em nós uma faculdade de resistência de espécie totalmente diversa, a qual nos encoraja a medir-nos com a parente onipotência da natureza ${ }^{22}$.

Em tal cena, o indivíduo se vê confrontado com elementos de uma força incomensurável que excedem, em dimensão e força, a sua própria constituição empírica. Por essa razão, além de configurar uma possibilidade efetiva de destruição, caso certa distância for transposta, também expressa a iminência da aniquilação como decorrente da mera constituição, tanto do objeto (queda d'água, por exemplo), quanto do indivíduo, no que se manifesta uma desproporção constitutiva primitiva. Contudo, propicia a emergência do sentimento do sublime justamente porque, podendo destruir, contudo, não destrói. E a razão para tal consiste em haver uma distância segura entre o indivíduo e o objeto, a partir do qual, emerge a evidência da superioridade do primeiro, enquanto ente racional, sobre a natureza ${ }^{23}$.

Embora Schopenhauer não acompanhe a Kant em dois pontos importantes - quais sejam: não concebe "a beleza como símbolo da moralidade", como Kant

\footnotetext{
22 KANT, I. Crítica da faculdade do juízo, p. 107.

${ }^{23}$ Nas Elegias de Duíno, Rilke, embora sem associar a possibilidade e a não efetividade da destruição ao sublime, mas ao belo, expressa uma imagem similar àquela apresentada por Kant, quando, na Primeira elegia, diz: "Pois o belo não é senão o princípio do espanto que mal conseguimos suportar, e ainda assim, o admiramos porque, sereno, deixa de nos destruir" (RILKE, R.M. Elegias de Duíno, p. 133).
} 
expressa explicitamente no parágrafo 59 da Crítica da faculdade do juízo (a beleza como a estação de partida para o trem da moral); não restringe o campo do sublime dinâmico à natureza. 0 vínculo entre a tragédia e o sublime dinâmico, como se verá a seguir, atesta tal recusa - ainda assim, é possível dizer que ele parece concordar com o restante da argumentação kantiana. No parágrafo 38, do Tomo I de $O$ Mundo, assim apresenta a diferença entre o belo e o sublime, retomando a distinção kantiana:

No belo o puro conhecimento ganhou a preponderância sem luta, pois a beleza do objeto, isto é, a sua índole facilitadora do conhecimento da Ideia, removeu da consciência, sem resistência e portanto imperceptivelmente, a Vontade e o conhecimento das relações [...]. O que aí resta é o puro sujeito, sem nenhuma lembrança da Vontade. No sublime, ao contrário, aquele estado de puro conhecimento é obtido por um desprender-se consciente e violento das relações do objeto com a Vontade conhecidas como desfavoráveis, mediante um livre elevar-se acompanhado de consciência para além da Vontade e do conhecimento que a esta se vincula ${ }^{24}$.

Destaque-se nessa passagem, o forte vínculo estabelecido entre o sentimento do sublime e a consciência. Em uma página, o termo é referido em seis ocasiões: "desviar-se da relação hostil com consciência", "desprender-se conscientemente", "desprender-se consciente e violento", "obter com consciência", "manter com consciência" e "entrar em cena na consciência". Tais ocorrências, nas quais é explicitado o sentido do sublime, funcionam, ao mesmo tempo, para fortalecer o argumento do vínculo proposto entre o sublime e o trágico, a partir do que é possível concluir que tal vínculo deve passar por um destaque dado à função, não da consciência enquanto elemento gerador do que está em causa, e sim, da apreensão, do tornar-se consciente do conflito entre Vontade, elevação por sobre a Vontade e seus motivos e a emergência do conhecimento da Ideia, portanto, da superação da vigência dos motivos. A tensão característica desse movimento, próprio ao sublime, não ao belo, constitui o próprio modo de ser do trágico. Dizer que a tragédia é o grau mais elevado do sentimento do sublime, é o mesmo que dizer que a tragédia é o desfile da tensão, da luta - personificada no herói como símbolo

${ }^{24}$ SCHOPENHAUER, A. MVR I, § 38, p. 274.

Resignação como efeito trágico: a teoria schopenhaueriana da tragédia 
- que, não se dando diretamente como no belo, só pode dar-se pela emergência de um "desprender-se consciente". A tensão, enquanto elemento característico da tragédia, mas também do sublime, revela “[...] o conflito da vontade consigo mesma"25. Contudo, o ponto mais radical da conjunção entre o sublime e o trágico consiste em que, a despeito da tensão, vincula-os o sobrepassar a tensão, "Pois assim como pela visão do sublime na natureza desviamo-nos do interesse da vontade para nos comportarmos de maneira contemplativa, assim também na catástrofe trágica desviamo-nos da Vontade de vida mesma"26.

Embora não haja uma diferença de natureza, e sim, de grau, de intensidade, entre o belo e o sublime, o sentimento mais aparentado ao que está em jogo na tragédia, tanto na realização artística quanto na apreensão do seu sentido, é o sublime, pois, tal como este, a tragédia também “[...] eleva-nos por sobre a Vontade e o seu interesse e dispõe nosso ânimo de tal forma que encontramos satisfação na vista daquilo que contradiz diretamente a Vontade"27, compartilhando tanto o contradizer a Vontade quanto a elevação por sobre ela.

Com essa maneira de ligar o trágico ao sublime, Schopenhauer resolve, ao seu modo, um dos problemas característicos da estética do idealismo alemão: a disputa entre o belo artístico e o belo natural, deslocando a discussão para um outro plano em que a oposição não mais vigora, tendo em vista que ambos os polos, embora distintos, surgem como configuração da Vontade.

Se não há oposição absoluta entre belo e sublime - pois "Apenas por um acréscimo é que o sentimento do sublime se distingue do belo" 28 -; e se a sua oposição não diz respeito ao objeto - pois "Quanto ao objeto [...] o belo e o sublime não são essencialmente diferentes"29 - ainda assim, há diferenças, e tudo o que foi dito parece suficiente para sustentar a existência de um vínculo forte entre o trágico e o sublime e, por consequência, entre o trágico e a resignação, pois a conjunção entre contradizer a Vontade e a elevação por sobre a Vontade compõem o ponto de encontro, a característica comum, que vincula o trágico ao sublime, não ao belo.

Importante destacar que, diferentemente de Aristóteles, para quem o

\footnotetext{
${ }^{25}$ SCHOPENHAUER, A. MVR I, §51, p. 333.

${ }^{26}$ SCHOPENHAUER, A. MVR II, §37, p. 519-520.

${ }^{27}$ Idem, p. 520.

${ }^{28}$ SCHOPENHAUER, A. MVR I, § 39, p. 274.

${ }^{29}$ SCHOPENHAUER, A. MVR I, § 41, p. 282.
} 
espetáculo trágico busca suscita as emoções "[...] da compaixão e do pavor" 30 , com vistas à catarse de tais emoções, Schopenhauer as vê como meios para um fim maior, precisamente o desvio da vontade de vida, a resignação. Por tal razão, mesmo quando o herói trágico não expressa tal tendência, o mais fundamental é que ela seja “[...] estimulada no espectador pela visão do grande sofrimento imerecido, ou mesmo merecido"31. E tal se explica ou justifica pela prioridade dada à contemplação enquanto ambiência da própria experiência estética. $\mathrm{Ou}$ seja, a contemplação efetiva a apreensão da Ideia. Neste ponto, insinuam-se outros grandes conceitos da estética ou da consideração metafísica do belo do sublime, tais como, intuição, gênio, imaginação, que, contudo, não serão aqui considerados 32 .

\section{Tragédia antiga e tragédia moderna}

Bem conhecida é a tentativa de posicionamento crítico de Nietzsche com relação à influência de Schopenhauer em $O$ nascimento da tragédia, feita por ele, tanto em sua Tentativa de autocrítica à sua primeira obra, de 1886, quanto em Ecce Homo, de 1888. Nietzsche lamenta ter “[...] obscurecido e estragado com fórmulas schopenhauerianas alguns pressentimentos dionisíacos"33. Também afirma que o livro tem "[...] cheiro indecorosamente hegeliano, é impregnado em apenas algumas fórmulas com o cadavérico aroma de Schopenhauer"34. Ou seja, o livro cheira mal. Mas, na passagem mais significativa a esse respeito, lemos uma espécie de sentença: "A tragédia precisamente é a prova de que os gregos não foram pessimistas: Schopenhauer enganou-se aqui, como se enganou em tudo"35.

Este juízo sobre a interpretação schopenhaueriana da tragédia tornou-se uma espécie de mantra hermenêutico a partir do qual se passou a ler, não apenas a primeira obra de Nietzsche, mas as próprias considerações schopenhauerianas

\footnotetext{
30 ARISTÓTELES, Poética, p. 73.

31 SCHOPENHAUER, A. MVR II, §37, p. 522.

32 Valeria a pena considerar o mistério contido na expressão "experiência contemplativa de apreensão da Ideia”. Ao fazê-lo seria necessário considerar o quão peculiar é esse tipo de conhecimento que se dá como um evento, um acontecimento (Ereigniss), não submetido ao Princípio de Razão Suficiente e configurado sob o modo de uma manifestação intensiva.

${ }^{33}$ NIETZSCHE, F.W. O nascimento da tragédia ou helenismo e pessimismo, p. 21.

${ }^{34}$ NIETZSCHE, F.W. Ecce homo - O nascimento da tragédia, p. 62.

35 Idem, p. 61.

Resignação como efeito trágico: a teoria schopenhaueriana da tragédia
} 
sobre a tragédia. Afinal, quem poderia resistir aos encantamentos báquicos de Dioniso? Contudo, ele é inexato e parcial. Para restituir a exatidão é o caso de mostrar que não apenas Schopenhauer reconhecia o caráter "afirmativo da tragédia grega" como via nisso um sinal de fraqueza, de imperfeição, razão pela qual concebia a tragédia moderna como superior à antiga.

O que é absolutamente imprescindível ao tratamento propriamente dito da tragédia, aquilo que constitui o caráter trágico no seu sentido mais primordial? Diz Schopenhauer: “Tão somente a exposição de uma grande infelicidade é essencial a ela"36. Mas, infelicidades, grandes infelicidades, as há de variados tipos. Tendo em vista o propósito de definir a tragédia, Schopenhauer distingue três causas distintas para o sofrimento, identificáveis nos recursos empregados pelos poetas desde a antiguidade na composição das peças trágicas, quais sejam:

1ํ. 0 evento trágico ocorre motivado por uma maldade extraordinária (Ricardo III; Creonte, de Antígona);

2‥ 0 evento trágico ocorre em função da ação do destino cego, portanto, por acaso e por erros (Édipo);

3ํ. 0 evento trágico é produzido "[...] pela mera disposição mútua das pessoas e combinação de suas relações recíprocas"37. Nesta acepção, o sofrimento não resulta de um erro monstruoso, do acaso inaudito, tampouco de um caráter malvado ou demoníaco. A disposição dos caracteres é de uma tal maneira que o simples fato de ser já é suficiente para que a desgraça seja engendrada. Sobre este último tipo de tragédia, Schopenhauer afirma:

[...] me parece superar em muito os anteriores, pois nos mostram a grande infelicidade não como exceção, não como algo produzido por circunstâncias raras ou caracteres monstruosos mas como algo que provém fácil e espontaneamente das ações e dos caracteres humanos, como uma coisa quase essencial, trazida terrivelmente para perto de nós ${ }^{38}$.

A diferença mais fundamental entre estes três tipos de tragédia consiste em que, enquanto nos dois primeiros, os eventos ocorrem em função de algo extraordinário (maldade extraordinária de um personagem ou ação do destino), no

\footnotetext{
${ }^{36}$ SCHOPENHAUER, A. MVR I, §51, p. 334.

${ }^{37}$ Idem, p. 335.

38 Ibidem.
} 
terceiro, os eventos resultam da simples constituição dos tipos humanos comuns. A mudança do extraordinário para o comum é o que marca a modificação estrutural da tragédia antiga para a moderna. A consequência mais decisiva dessa mudança para a compreensão do trágico, de acordo com Schopenhauer, é que "Nas duas primeiras técnicas vemos o destino monstruoso e a maldade atroz que, no entanto, ameaçam só de longe, por conseguinte temos a esperança de nos subtrair a eles sem necessidade de nos refugiarmos na renúncia"39, enquanto que na última, as potências destrutivas, visto não resultarem de algo extraordinário, mas comum, podem, a qualquer instante nos atingir; seja porque poderiam ser produzidas por qualquer um a nossa volta, seja porque poderíamos nós próprios produzi-las.

O espírito da terceira espécie de tragédia é tipicamente moderno, enquanto que a disposição das duas primeiras espécies caracteriza a marca distintiva das tragédias antigas. Se no primeiro caso, o reconhecimento da maldade e do sofrimento não resulta da identificação de causas externas ou longínquas, que agem à distância, mas da própria constituição do humano, torna-se plausível a afirmação schopenhaueriana que a tragédia moderna conduz à resignação, não meramente à compaixão e ao pavor, pois engendra, no reconhecimento, a identificação da causa do mal em si próprio, levando a aceitar que o melhor seria não querer, mesmo que isso ainda não signifique que o reconhecimento produza firme constância que mantém a vigência da negação da Vontade. Resignar-se é reconhecer a fonte do mal, aceitar essa verdade. Por sua vez, os antigos ainda se mantinham fortemente ligados à esperança. A esse respeito, no $\$ 37$ dos Suplementos, é possível ler:

Concedo que na tragédia dos antigos raras vezes vemos esse espírito de resignação entrar em cena e expressar-se diretamente. Édipo em Colono decerto morre resignado e voluntariamente; porém ele se consola com a vingança exercida contra sua pátria. Ifigênia em Aúlide está completamente disposta a morrer; porém, o que a consola e produz a mudança de sua disposição moral é pensar no bem da Grécia ${ }^{40}$.

Por essa razão, Schopenhauer conclui: “[...] sou da opinião de que a tragédia dos modernos encontra-se num patamar mais elevado que a dos antigos.

39 Ibidem.

40 SCHOPENHAUER, A. MVR II, §37, p. 520.

Resignação como efeito trágico: a teoria schopenhaueriana da tragédia 
Shakespeare tem uma grandeza bem superior à de Sófocles"41. Assim, diferentemente do que pensava Nietzsche, Schopenhauer sabia do caráter não resignado, ou suficientemente resignado dos personagens das tragédias dos antigos; e precisamente nessa falha amparou a eleição dos modernos como mestres da arte trágica.

Por fim, caberia uma última observação sobre a suposta incompreensão da tragédia antiga por parte de Schopenhauer, afirmada por Nietzsche, agora voltada contra o acusador e crítico. Ao interpretar a tragédia grega, Nietzsche não percebeu o fundo de esperança que motivava muitos dos personagens e que constituía, senão o telos da peça, ao menos, formava o nexo organizador da ação do herói. Édipo, em Édipo em Colono, é movido pela esperança de vingar-se contra sua terra natal, não pelo imperativo da afirmação incondicional da vida, do sagrado dizer sim à vida. Também Prometeu, aquele que Nietzsche chamava de o "herói ativo" do palco grego, é movido, pelo ressentimento a Zeus. É o ressentimento que o faz falar, calar e esperar o tempo em que Zeus se curvará e solicitará seus préstimos numa aliança futura contra os Titãs.

Esperança e ressentimento: algo cuja presença Nietzsche não apreendeu suficientemente na tragédia grega e de cuja presença não encontramos nenhum indício na interpretação schopenhaueriana da tragédia. Assim, Schopenhauer não "se enganou em tudo"; ao menos, não neste ponto em particular.

\section{Referências bibliográficas}

ARISTÓTELES. Poética. Trad. Paulo Pinheiro. São Paulo: Editora 34, 2015.

GOETHE, J.W. Fausto, uma tragédia - Primeira parte. Trad. Jenny Klabin Segall. São Paulo: Editora 34, 2004.

GOETHE, J.W. Fausto, uma tragédia - Segunda parte. Trad. Jenny Klabin Segall, $2^{\text {a }}$ Ed. São Paulo: Editora 34, 2008.

KANT, I. Crítica da faculdade do juízo. Trad. António Marques e Valério Rohden, 2aㅡ Ed. Rio de Janeiro: Forense Universitária, 1995.

NIETZSCHE, F.W. Ecce homo - ou como alguém se torna o que é. Trad. Paulo César de Souza. São Paulo: Companhia das Letras, 1995.

NIETZSCHE, F.W. O nascimento da tragédia ou helenismo e pessimismo. Trad. J. Guinsburg. São Paulo: Companhia das Letras, 1992.

RILKE, R.M. Sonetos a Orfeu / Elegias de Duíno. Trad. Emmanuel Carneiro Leão. Petrópolis, RJ: Vozes, 1989.

SCHOPENHAUER, A. O mundo como vontade e representação - Primeiro tomo. Trad. Jair

41 Idem, p. 521. 
Barboza. São Paulo: Editora da UNESP, 2005.

SCHOPENHAUER, A. O mundo como vontade e representação - Segundo tomo (Suplementos). Trad. Jair Barboza. São Paulo: Editora da UNESP, 2015.

SÓFOCLES. Édipo em colono. Trad. Trajano Vieira. São Paulo: Perspectiva, 2005.

SZONDI, P. Ensaio sobre o trágico. Trad. Pedro Süssekind. Rio de Janeiro: Jorge Zahar Editor, 2004.

Recebido: $14 / 01 / 18$

Received: $01 / 14 / 18$

Aprovado: $19 / 01 / 18$

Approved: 01/19/18 